Research Article

\title{
Coupling Coordination of Water Governance and Tourism: Measurement and Prediction
}

\author{
Yuqing Geng (D), Mukasar Maimaituerxun (D), and Han Zhang ${ }^{\mathbb{D}}$ \\ School of Business, Shanghai Dianji University, Shanghai 201306, China \\ Correspondence should be addressed to Yuqing Geng; gengyq@sdju.edu.cn and Mukasar Maimaituerxun; mukasar@foxmail.com
}

Received 15 January 2020; Accepted 22 February 2020; Published 17 March 2020

Academic Editor: Ewa Pawluszewicz

Copyright (c) 2020 Yuqing Geng et al. This is an open access article distributed under the Creative Commons Attribution License, which permits unrestricted use, distribution, and reproduction in any medium, provided the original work is properly cited.

\begin{abstract}
The interaction between water governance and tourism is complicated and significant so that the study of the coupling coordination between these two subsystems is important. This study analyzes the correlation mechanism of the water governancetourism system, constructs the composite and aggregated evaluation system which consists of 5 dimensions and 15 indicators, uses information entropy weight technique for order preference by similarity to an ideal solution method to evaluate the development degrees of both water governance and tourism growth of the 11 regions in the Yangtze River Economic Zone, analyzes the two subsystems' relation of coupling coordination temporally and spatially with the coupling coordination degree model, predicts degrees of coupling coordination of the regions for the next 4 years with gray system prediction model, and proposes specific and generalizable countermeasures. The results show that these methods can provide an effective reference to evaluate the coupling coordination development of water governance and tourism and to provide scientific and generalizable countermeasures for enhancement.
\end{abstract}

\section{Introduction}

There is a complex correlation between water governance and tourism, which has aroused widespread concern in the academic community [1]. Benign water governance is one of the prerequisites and meanwhile is an effective tool for tourism growth [2]. Thus, improving water quality and water governance are necessary for tourism growth. Water governance impacts on tourism both positively and negatively: attractive water resources can promote better development of tourism, such as lake tourism and marine tourism [2,3]; water pollution can also negatively affect the tourism [4]. Currently, for many places in the world, the water environment is a significant highlight for the sustainable tourism business, but with the development of tourism, water resources have also become one of the important restricting factors. For example, according to the statistics of the Ministry of Water Resources of China, there were over 400 cities suffering unqualified water resources in 2019, accounting for about $60 \%$ of the country's cities, and the tourism of these regions is accordingly affected and hindered by such status.
Tourism has generated much influence on the local water governance in either negative or positive manner: tourism itself increases the pressure on the water environment and causes water pollution [5], but it helps improve water quality if tourism activities are planned scientifically [6]. For example, according to the statistics of the Ministry of Culture and Tourism of China, the number of tourists in China was about 5.7 billion in 2018, and the total revenue was about 860 billion US dollars. The development of tourism in China was relatively satisfying, but through tourism-related activities such as tourists' consumption and accommodation, tourism has affected water governance from different perspectives. Meanwhile, currently, certain authorities have initiated tourism marketing programs with highlights of excellent water resources, which in turn facilitates the determination and decisiveness of water governance. Therefore, there is a need to deepen the study of the relation of coupling coordination between water governance and tourism, explore the water governance and tourism development with sustainability, and maintain them at relatively high and satisfying levels. 


\section{Literature Review}

Water governance refers to the stable, comprehensive, dynamic, and integrated structure and function of water resources, which provides reliable water ecological services for human activities [7]. Water governance depicts the status of the ecological environment and the risks or dynamics of human activities related to the water environment [8]. Tourism refers to a kind of human activity where individuals go to places which they do not usually live in for travelling and accommodating for a while [9]. Tourism covers tourism-related events such as cuisine, transportation, accommodation, entertainment, attractions, tourism trade, and tourism events. Water governance has similarities to tourism because these two subsystems contain some of the same functional factors such as human activities; however, these two subsystems are different because the water environment is an ecosystem while tourism is an industry.

2.1. The Impact of Water Governance on Tourism. Studies show that water governance can positively or negatively affect tourism. The improved water governance benefits tourism growth and provides another development path for the tourism industry [10]. A good image of water governance increases the competitiveness and attractiveness of a tourism destination; good water governance illustrates that the destination has attractive scenery and resources for aquatic tourism activities [11]. At the same time, the good water governance depends on the investment and construction of environment-related infrastructures, such as processing facilities, high-quality water resources, and scientific public governance, which indirectly promotes the sustainable development of tourism [12]. In addition, taxes from water environmental governance provide benefits for reducing water pollution and promoting tourism development [13]. For instance, some regions have initiated plans to improve water governance, and those with better water governance have become famous tourism destinations. Qinghai Province in China positions its tourism as "the origin place of the three vital rivers in China" in tourism marketing, highlighting its tourism attractiveness and benefiting from the water governance.

At the same time, some tourism destinations regard the water governance as an important resource or a carrier to promote tourism activities; however, inappropriate use and the use of inferior water resources have led to negative impacts on tourism, such as the spread of disease and tourists' dissatisfaction [14]. Problems related to water governance damage the image and reputation of tourism destinations, reduce tourists' evaluation of the destinations, and further hinder the development of the local tourism industry [15]. Therefore, some studies have investigated tourism development with sustainability from the perspective of water governance, such as tourism environment sustainability, and tourism environmental quality and measurement [16, 17].
2.2. The Impact of Tourism on Water Governance. Water-related tourism issues have attracted much attention. Tourism is correlated to water governance: tourism can positively or negatively affect the water environment and its governance. On the one hand, tourism activities positively affect the changes of the water governance; tourism industry with sustainability helps the public to set up awareness or attitudes on water environmental protection, and the ethics of the water governance can balance the relationship between tourism activities and water environmental protection [18]. In addition, tourism activities promote the upgrading of regional functions and industrial structures of tourism destinations, which helps to better accelerate water governance [19]. Cases in some regions have shown that tourism, as a means of economic growth, can help promote local water governance [20].

On the other hand, tourism activities cause pressure on water governance. Tourism activities have relatively serious negative impacts on water governance (e.g., water pollution and water waste) [21]. At the same time, through entertainment, accommodation, transportation, and so on, tourism activities change the form of energy consumption, increase the burden on water governance, and even have a negative impact on the water governance [22, 23]. Some scholars have discussed the negative impact of tourism on water governance in different regions based on qualitative or quantitative analysis [24, 25].

\subsection{The Interaction between Water Governance and Tourism.} There are components that change with time in the two subsystems of water governance and tourism, so the interaction between these two subsystems is complicated [26]. Coupling refers to the situation in which subsystems interact with and affect each other [27]. Water governance and tourism interact and influence each other; therefore, the coupling can be effectively used to evaluate the interaction between these two subsystems. The degree of coupling coordination reflects the trend that the system changes to the ordered state from the disordered state, which is conducive to the harmonious development and promoting positive interactions between subsystems [28]. Existing studies have measured the coupling coordination relationship between environmental governance and tourism in different regions and emphasized the importance of the coupling between environmental governance and tourism [29, 30], whereas coupling coordination analysis should be further used to study the interaction between water governance and tourism.

There is much interest in water governance and tourismrelated research. However, there are currently no widely accepted and suitable indicator systems to evaluate the coupling coordination relationship of these two subsystems; therefore, it is difficult to explore the coordination relationship of coupling between these subsystems appropriately, accurately, dynamically, and comprehensively. Besides, previous research mostly emphasized the two subsystems' impact mechanism, while, in fact, a new 
consensus on the interaction between the two subsystems from a new perspective, which is coupling coordination, should be found. Besides, by using an independent region as the research case, most studies ignore the spatial-temporal comparisons and predictions among different regions or places. Hence, to discover the relation of coupling coordination between the subsystems of water governance and tourism in different regions spatially and temporally is necessary and significant.

\section{Study Area}

Located in the south of China, the Zone consists of 2 municipalities (Chongqing and Shanghai) and 9 provinces (Hubei, Hunan, Jiangxi, Jiangsu, Anhui, Zhejiang, Sichuan, Yunnan, and Guizhou) (Figure 1) and covers an area of about 20,500 square kilometers (about 21\% of China's land area). The Zone is China's National Strategic Development Zone with its population number, gross domestic product (GDP), and the tertiary industry output accounting for over $39 \%$ in China. The Zone enjoys benign water resources and overall water quality: the total volume of water resources accounted for more than $30 \%$ of the total runoff of rivers in the country, and the proportion of Class I to III water was more than $70 \%$ in 2018. Besides, the Zone is good in tourism: the number of national forest parks, wetland parks, scenic spots, and nature reserves was more than $40 \%$ of the country by the end of 2018. However, there are obvious regional differences in water governance, distribution of water and tourism resources, and tourism development. The interaction between water governance and tourism has become a serious issue for water governance and tourism development with sustainability in the region. Therefore, selecting the 11 regions of the Zone as the case and comparing and predicting the spatial-temporal differences are representative and significant to optimize the interregional industrial structure and promote regional water governance and sustainable development of tourism.

\section{Materials and Methods}

This study uses the statistical data of China's Yangtze River Economic Zone (the Zone) from 2009 to 2018, firstly constructs a composite and aggregate evaluation system for the coupling coordination relationship between the two subsystems of water governance and tourism, secondly measures the development degrees (DD) of water governance and tourism growth, respectively, with the method of information entropy weight technique for order preference by similarity to an ideal solution, thirdly evaluates the degrees of coupling coordination (DCC) between the two subsystems by using the coupling coordination degree model, and fourthly predicts the tendency of the coupling coordination development between the two subsystems in the next four years by using the gray system prediction model. The study aims to (1) investigate the development degrees of the water governance and tourism in the Zone between 2009 and 2018, (2) study the spatial and temporal differences and predict the trends of the relation of coupling coordination of the water governance-tourism system, and (3) provide specific while generalizable countermeasures for policy making of water governance and tourism industry with sustainability.

4.1. Evaluation System Construction. There are complex interactions between water governance and tourism. Good water governance can be used as a tool to accelerate tourism growth sustainably; conversely, water pollution can hinder the tourism business and threaten the attractiveness of tourism destinations. Besides, tourism activities can support the effectiveness of water governance and the sustainable use of water resources and can also restrain water governance through tourism activities as well. Therefore, water governance and tourism can be regarded as two subsystems, which together form the system for coupling and which affect and interact with each other. The correlation mechanism of the water governance-tourism system is shown in Figure 2.

Based on the coupling coordination mechanism and previous research, this study selects key indicators to study the coupling coordination interactions between the two subsystems after qualitative analysis, correlation coefficients, and comparison of significance levels [31]. In this study, the water governance-tourism evaluation system consisting of two subsystems (water governance and tourism), 5 dimensions, and 15 indicators is established, as shown in Table 1.

In the water governance subsystem, the Pressure-StateResponse model is used in order to assess the interaction mechanism of water governance and to set up the evaluation system. Water governance pressure represents the pressure of water pollution, including the discharge of wastewater, COD, and ammonia nitrogen $[28,32,33]$. The water governance state represents the current status of water resources, including two indicators: the number of water resources and the amount of water use per capita [33,34]. Water governance response represents the management and protection of water resources, including the investment in wastewater treatment projects, wastewater treatment rate, and volume of water saved per capita $[35,36]$. In the tourism subsystem, tourism performance represents the revenue and financial situation of the tourism industry, including international and domestic tourism revenues $[37,38]$; tourism scale represents the overall size of the industry of tourism, which covers the numbers of tourists both internationally and domestically, and the numbers of hotels, tourism practitioners, and travel agencies [38-41].

4.2. Data Collection and Preprocessing. The data in this study are from China Statistical Yearbook on Environment (2009 to 2018), Yearbook of China Tourism Statistics (2009 to 2018), Yearbook of China Tourism (2009 to 2018), Yangtze River Yearbook (2009 to 2018), and China Statistical Yearbook (2009 to 2018).

(1) Standardize the indicator with formula (1) if it is negative and with formula (2) if it is positive: 


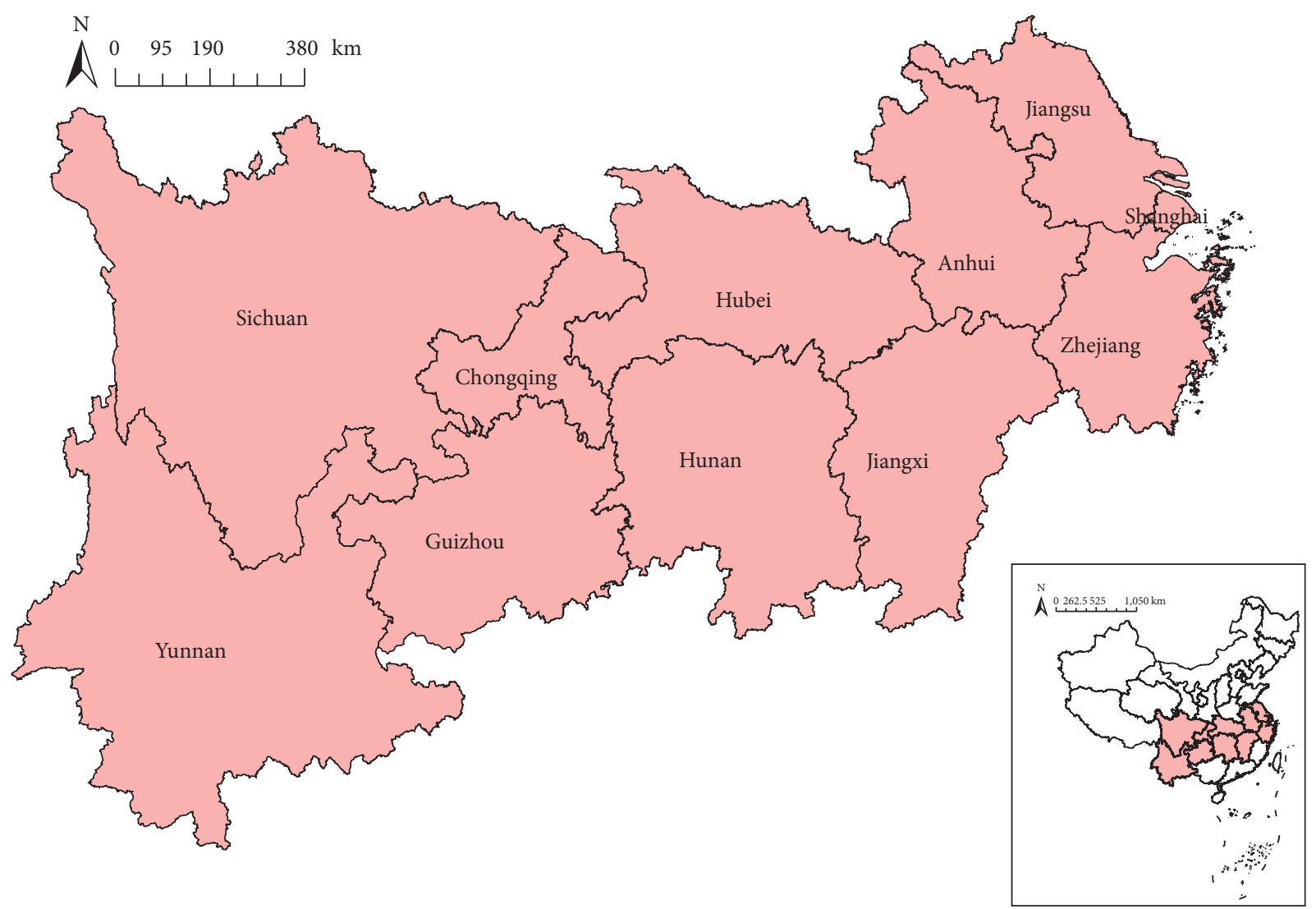

Figure 1: Study area.

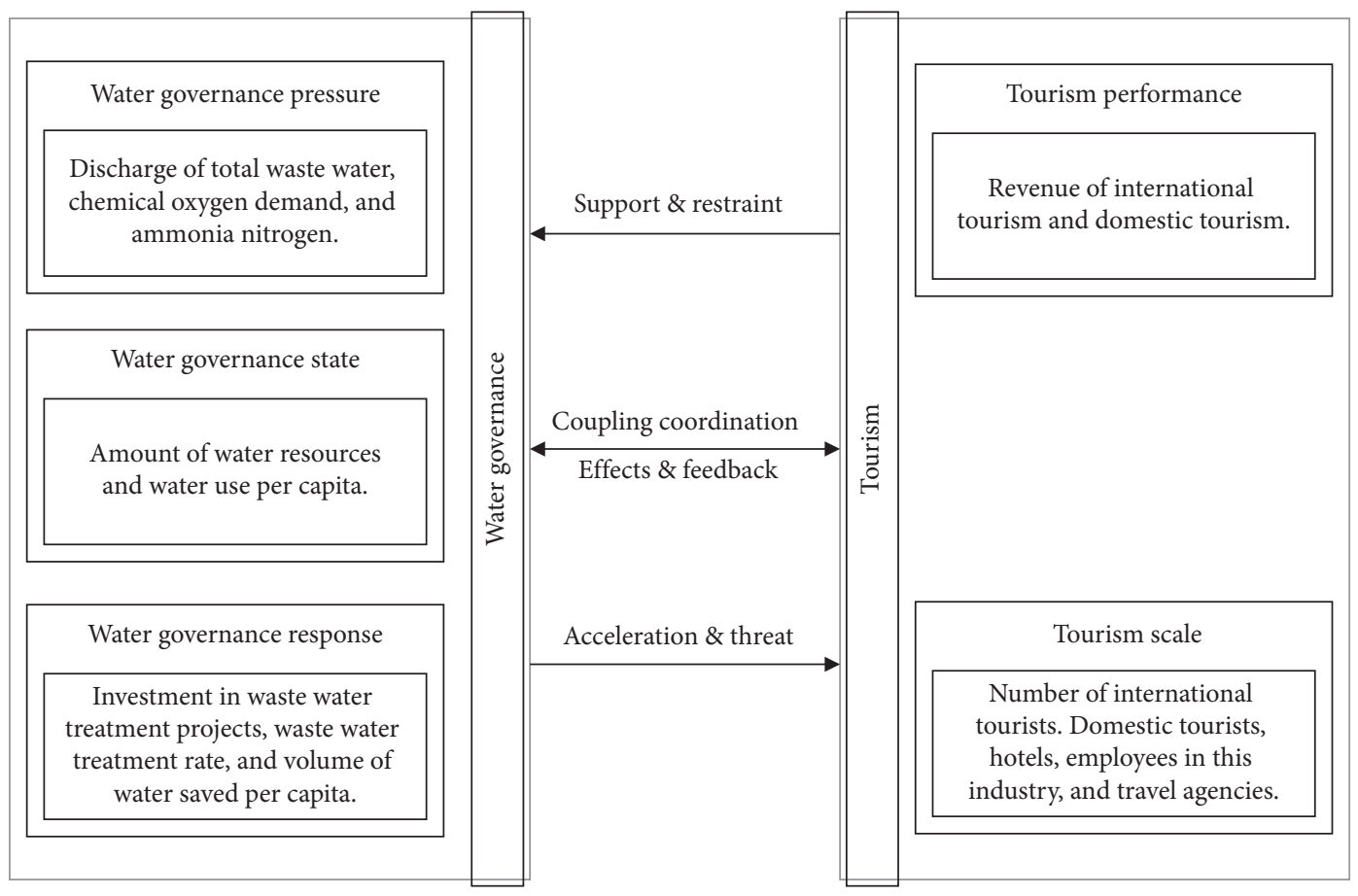

FIGURE 2: Correlation mechanism of water governance-tourism system. 
TABLE 1: Water governance-tourism evaluation system.

\begin{tabular}{|c|c|c|c|}
\hline Subsystem & Dimension & Indicator & Interpretation \\
\hline \multirow{7}{*}{$\begin{array}{l}\text { Water } \\
\text { governance }\end{array}$} & \multirow{3}{*}{$\begin{array}{l}\text { Water governance } \\
\text { pressure }\left(W_{1}\right)\end{array}$} & Total wastewater discharged $\left(w_{1,-}\right)^{1}$ & Reflects the overall water pollution pressure \\
\hline & & Chemical oxygen demand discharged $\left(w_{2,-}\right)$ & $\begin{array}{l}\text { Reflects the pollution pressure from chemical } \\
\text { oxygen demand }\end{array}$ \\
\hline & & Ammonia nitrogen discharged $\left(w_{3,-}\right)$ & $\begin{array}{c}\text { Reflects the pollution pressure from ammonia } \\
\text { nitrogen }\end{array}$ \\
\hline & \multirow{2}{*}{$\begin{array}{l}\text { Water governance state } \\
\qquad\left(W_{2}\right)\end{array}$} & Total amount of water resources $\left(w_{4,+}\right)$ & $\begin{array}{l}\text { Reflects the current state of the water } \\
\text { resources }\end{array}$ \\
\hline & & Volume of water use per capita $\left(w_{5,+}\right)$ & Reflects the current state of the water use \\
\hline & \multirow{2}{*}{$\begin{array}{l}\text { Water governance } \\
\text { response }\left(W_{3}\right)\end{array}$} & $\begin{array}{l}\text { Investment completed in wastewater } \\
\text { treatment projects }\left(w_{6,+}\right)\end{array}$ & Reflects the investment of water governance \\
\hline & & $\begin{array}{l}\text { Wastewater treatment rate }\left(w_{7,+}\right) \\
\text { Volume of water saved per capita }\left(w_{8,+}\right)\end{array}$ & $\begin{array}{l}\text { Reflects the treatment degree of wastewater } \\
\text { Reflects the saved degree of water }\end{array}$ \\
\hline \multirow{7}{*}{ Tourism } & \multirow{3}{*}{ Tourism performance $\left(T_{1}\right)$} & International tourism revenue $\left(t_{1,+}\right)$ & Reflects the performance of inbound tourism \\
\hline & & Domestic tourism revenue $\left(t_{2,+}\right)$ & Reflects the performance of domestic tourism \\
\hline & & Number of international tourists $\left(t_{3,+}\right)$ & Reflects the scale of inbound tourism \\
\hline & \multirow{4}{*}{ Tourism scale $\left(T_{2}\right)$} & Number of domestic tourists $\left(t_{4,+}\right)$ & Reflects the scale of domestic tourism \\
\hline & & Number of hotels $\left(t_{5,+}\right)$ & Reflects the scale of accommodation services \\
\hline & & $\begin{array}{l}\text { Number of employees in tourism industry } \\
\qquad\left(t_{6,+}\right)\end{array}$ & $\begin{array}{l}\text { Reflects the scale of human resources of the } \\
\text { industry }\end{array}$ \\
\hline & & Number of travel agencies $\left(t_{7,+}\right)$ & Reflects the scale of tourism services providers \\
\hline
\end{tabular}

${ }^{1}+$ represents positive; - represents negative.

$$
\begin{aligned}
& x_{i j}^{\prime}=1-\frac{x_{i j}}{\sum_{i=1}^{n} x_{i j}}, \\
& x_{i j}^{\prime}=\frac{x_{i j}}{\sum_{i=1}^{n} x_{i j}} .
\end{aligned}
$$

Here, $x_{i j}$ is the matrix $X$ of alternative $i$ under the indicator $j$ of all the years; $x^{\prime}=\left(x_{i j}^{\prime}\right)_{m \times n}$ is the matrix after standardization; $\min _{1 \leq j \leq n} x_{i j}$ and $\max _{1 \leq j \leq n} x_{i j}$ are the minimum and maximum values in indicator $j$ among all the years.

(2) Calculate $\ln f_{i j}$ to avoid insignificance:

$$
f_{i j}=\frac{1+x_{i j}^{\prime}}{\sum_{i=1}^{m}\left(1+x_{i j}^{\prime}\right)} .
$$

(3) Calculate the information entropy depending upon the matrix $x^{\prime}$ :

$$
H_{j}=-\left(\sum_{i=1}^{m} f_{i j} \ln f_{i j}\right), \quad i=1,2, \ldots, m ; j=1,2, \ldots n .
$$

(4) Calculate the deviations in the coefficients of indicators $j\left(G_{j}\right)$ :

$$
G_{j}=1-H_{j}, \quad j=1,2, \ldots n .
$$

(5) Calculate the weight $w_{j}$ of the indicator $j$ :

$$
w_{j}=\frac{G_{j}}{\sum_{j=1}^{n} G_{j}}=\frac{1-H_{j}}{n-\sum_{j=1}^{n} H_{j}} .
$$

\subsection{DD Calculation}

(1) Calculate the positive ideal solution with formula (7) and the negative ideal solution with formula (8). The MPA $X^{+}$represents the most preferred alternative; the LPA $X^{-}$represents the least preferred alternative:

$$
\begin{aligned}
& X^{+}=\left(\max _{1 \leq i \leq m} x_{i 1}, \max _{1 \leq i \leq m} x_{i 2}, \ldots, \max _{1 \leq i \leq m} x_{i n}\right), \\
& X^{-}=\left(\min _{1 \leq i \leq m} x_{i 1}, \min _{1 \leq i \leq m} x_{i 2}, \ldots, \min _{1 \leq i \leq m} x_{i n}\right) .
\end{aligned}
$$

(2) Calculate the separation degrees from the LPA to MPA:

$$
\begin{aligned}
& \mathrm{SD}_{i}^{+}=\sqrt{\sum_{j=1}^{n} w_{i}\left(x_{i j}-x_{j}^{+}\right)^{2}}, \quad i=1,2, \ldots, m ; 0 \leq \mathrm{SD}_{i}^{+} \leq 1, \\
& \mathrm{SD}_{i}^{-}=\sqrt{\sum_{j=1}^{n} w_{j}\left(x_{i j}-x_{j}^{-}\right)^{2}}, \quad i=1,2, \ldots, m ; 0 \leq \mathrm{SD}_{i}^{-} \leq 1 .
\end{aligned}
$$

(3) Calculate the DD of the subsystem:

$$
\mathrm{DD}=\frac{\mathrm{SD}_{i}^{-}}{\mathrm{SD}_{i}^{+}+\mathrm{SD}_{i}^{-}}, \quad i=1,2, \ldots, m ; 0 \leq \mathrm{DD} \leq 1
$$


Here, the evaluation grade of the DD of the subsystem is established (Table 2). The grade is built by the equalization concept, which objectively ensures equality among intervals.

\subsection{Calculation}

(1) Calculate $C$, the coupling degree of the water governance-tourism system. $H(x)$ represents the DD of the water governance subsystem; $Q(y)$ represents the DD of the tourism subsystem:

$$
C=\left\{\frac{H(x) \times Q(y)}{((H(x)+Q(y)) / 2)^{2}}\right\}^{1 / 2} .
$$

(2) Calculate $M$, the DCC of the water governancetourism system, to evaluate the two subsystems' interaction. $\sigma$ and $\varphi$ are the coefficients; we hereby define $\sigma=\varphi=0.5$ considering the equal importance of the two subsystems [42]:

$$
M=\sqrt{C \times(\sigma H(x)+\varphi Q(y))} .
$$

The classification of DCC is constructed based on former research (Table 3) [43].

\subsection{Prediction}

(1) For the original series $X_{0}=\left\{x_{0}(1), x_{0}(2), \ldots\right.$, $\left.x_{0}(n)\right\}$, there are $n$ observations; the sequence $x_{1}(t)=\sum_{i=1}^{t} x_{0}(i)$ is used to get the new sequence $X_{1}=\left\{x_{1}(1), x_{1}(2), \ldots, x_{1}(n)\right\}$. Then, calculate the differential equation:

$$
\mu=\frac{\mathrm{d} x_{1}(t)}{\mathrm{d} t}+\alpha x_{1}(t)
$$

where $\mu$ is the gray number of endogenous controls and $\alpha$ is the gray number of developments.

(2) $\widehat{a}=(\alpha / \mu)=\left(B^{T} B\right)^{-1} B^{T} Y$ is the estimated parameter vector. $B=\left[-Z_{1}(2),-Z_{1}(3), \ldots,-Z_{1}(n), 1,1, \ldots, 1\right]^{T}$ and $Y=\left[x_{0}(2), \ldots, x_{0}(n)\right]^{T}$; then, we obtain the cumulative sequence prediction model as follows:

$$
\widehat{x}(t+1)=\left[x_{0}(1)-\frac{\mu}{\alpha}\right] e^{-\alpha t}+\frac{\mu}{\alpha}, \quad t=1,2, \ldots, n .
$$

In order to test the model's accuracy, the indicator $a$ is used. If $a \leq 0.5$, the data are applicable to predict the tendencies [44]. Calculate the residual difference $\varepsilon_{0}(t)$ with formula (15) and the relative error value $q(t)$ of $x_{0}$ with formula (16):

$$
\begin{aligned}
& \varepsilon_{0}(t)=x_{0}(t)-\widehat{x}_{0}(t), \\
& q(t)=\frac{\varepsilon_{0}(t)}{x_{0}(t)} \times 100 \% .
\end{aligned}
$$

TABLE 2: Evaluation grades of DD.

\begin{tabular}{ccccc}
\hline Value & $\mathrm{DD} \geq 0.75$ & $0.75>\mathrm{DD} \geq 0.50$ & $0.50>\mathrm{DD} \geq 0.25$ & $0.25>\mathrm{DD}$ \\
\hline Grade & Excellent & Good & Acceptable & $\mathrm{Bad}$
\end{tabular}

TABLE 3: Classification of DCC.

\begin{tabular}{lcc}
\hline Range & Value of $M$ & Classification \\
\hline Coordinated & $1 \geq M \geq 0.8$ & $\begin{array}{c}\text { High coordination } \\
\text { (acceptable) }\end{array}$ \\
& $0.8>M \geq 0.7$ & $\begin{array}{c}\text { Intermediate } \\
\text { coordination }\end{array}$ \\
& $0.7>M \geq 0.6$ & Primary coordination \\
\hline \multirow{2}{*}{ Transitional coordinated } & $0.6>M \geq 0.5$ & Reluctant coordination \\
& $0.5>M \geq 0.4$ & Approaching imbalance \\
\hline \multirow{2}{*}{ Imbalanced } & $0.4>M \geq 0.3$ & Slight imbalance \\
(unacceptable) & $0.3>M \geq 0.2$ & Moderate imbalance \\
& $0.2>M \geq 0$ & High imbalance \\
\hline
\end{tabular}

$\bar{\varepsilon}_{0}=(1 / n-1) \sum_{t=2}^{n} \varepsilon_{0}(t)$ is the mean of the residual $\varepsilon_{0}(t) ;$ $S_{\varepsilon}^{2}=(1 / n-1) \sum_{t=2}^{n}\left(\varepsilon_{0}(t)-\bar{\varepsilon}_{0}\right)^{2}$ is the variance of $\varepsilon_{0}(t) ; \bar{x}_{0}=$ $(1 / n-1) \sum_{t=2}^{n} x_{0}(t)$ is the mean of the residual $x_{0}(t) ; S_{x}^{2}=$ $(1 / n-1) \sum_{t=2}^{n}\left(x_{0}(t)-\bar{x}_{0}\right)^{2}$ is the variance of $x_{0}(t)$. Calculate the variance ratio $C=\left(S_{\varepsilon} / S_{x}\right)$ and the small error probability $P=p\left(\left|\varepsilon_{0}(t)-\bar{\varepsilon}_{0}\right|<0.6745 S_{x}\right)$. The model is valid if $r \geq 0.60, C \leq 0.80$, and $P \geq 0.60$ [45].

\section{Results and Discussions}

5.1. System's DD Analysis. Table 4 shows the DD of the water governance subsystem. In general, in these 11 regions, the DDs of the water governance subsystem are averagely lower and more fluctuant than those of the tourism subsystem. The first category "good" (0.50-0.75) only includes Shanghai, two fewer than the category "good" in the tourism subsystem. Shanghai's DD showed a fluctuating tendency: acceptable (2009-2010) to good (2011-2016) and then back to an acceptable grade (2017-2018). On the contrary, Chongqing fell into the third category "bad" (0-0.25), which mainly stayed at a low level. The rest 9 regions were in the second category "acceptable" (0.25-0.50). In detail, Anhui and Hubei witnessed great changes: Anhui fell from "good" (0.738) in 2009 to "acceptable" (0.313) in 2018, while Hubei increased from "acceptable" (0.275) in 2009 to "excellent" (0.757) in 2018.

Table 5 shows the DD of the tourism subsystem. In general, the DDs of tourism in the 11 regions are not high, and the values fluctuate softly with upward trends. The first category is "good" (0.50-0.75), including Shanghai, Jiangsu, and Zhejiang. Though they had relatively satisfied development capacity of tourism, all of them had declining trends. The second is "acceptable" (0.25-0.50), including the rest 7 regions except Guizhou, demonstrating an acceptable development capacity with upward trends. The third category is "bad" $(0-0.25)$, including Guizhou only, which had a relatively fast development speed from "bad" (0.080) in 2009 to "acceptable" (0.295) in 2018. The DD of tourism is higher than that of water governance mainly because the investment of water 
TABLE 4: DD of water governance subsystem.

\begin{tabular}{lllllllllllll}
\hline & 2009 & 2010 & 2011 & 2012 & 2013 & 2014 & 2015 & 2016 & 2017 & 2018 & Mean & Grade \\
\hline Chongqing & 0.173 & 0.174 & 0.270 & 0.254 & 0.233 & 0.210 & 0.206 & 0.221 & 0.129 & 0.143 & 0.201 & Bad \\
Shanghai & 0.348 & 0.353 & 0.641 & 0.596 & 0.611 & 0.562 & 0.577 & 0.593 & 0.396 & 0.465 & 0.514 & Good \\
Hubei & 0.275 & 0.243 & 0.415 & 0.409 & 0.379 & 0.345 & 0.349 & 0.372 & 0.746 & 0.757 & 0.429 & Acceptable \\
Hunan & 0.176 & 0.209 & 0.356 & 0.327 & 0.372 & 0.356 & 0.315 & 0.362 & 0.231 & 0.251 & 0.295 & Acceptable \\
Jiangxi & 0.164 & 0.136 & 0.289 & 0.292 & 0.310 & 0.314 & 0.289 & 0.343 & 0.207 & 0.219 & 0.256 & Acceptable \\
Jiangsu & 0.330 & 0.315 & 0.582 & 0.558 & 0.479 & 0.625 & 0.611 & 0.613 & 0.395 & 0.473 & 0.498 & Acceptable \\
Anhui & 0.738 & 0.768 & 0.301 & 0.423 & 0.431 & 0.453 & 0.439 & 0.434 & 0.317 & 0.313 & 0.462 & Acceptable \\
Zhejiang & 0.464 & 0.242 & 0.446 & 0.439 & 0.462 & 0.518 & 0.519 & 0.539 & 0.372 & 0.398 & 0.440 & Acceptable \\
Yunnan & 0.185 & 0.159 & 0.305 & 0.362 & 0.406 & 0.323 & 0.324 & 0.364 & 0.218 & 0.212 & 0.286 & Acceptable \\
Sichuan & 0.219 & 0.286 & 0.345 & 0.385 & 0.383 & 0.355 & 0.365 & 0.388 & 0.237 & 0.384 & 0.335 & Acceptable \\
Guizhou & 0.239 & 0.226 & 0.415 & 0.242 & 0.348 & 0.293 & 0.292 & 0.294 & 0.187 & 0.224 & 0.276 & Acceptable \\
\hline
\end{tabular}

TABLE 5: DD of tourism subsystem.

\begin{tabular}{lllllllllllrrrr}
\hline & 2009 & 2010 & 2011 & 2012 & 2013 & 2014 & 2015 & 2016 & 2017 & 2018 & Mean & Grade \\
\hline Chongqing & 0.207 & 0.236 & 0.245 & 0.280 & 0.293 & 0.284 & 0.283 & 0.285 & 0.301 & 0.325 & 0.274 & Acceptable \\
Shanghai & 0.619 & 0.618 & 0.666 & 0.632 & 0.585 & 0.598 & 0.583 & 0.557 & 0.579 & 0.585 & 0.602 & Good \\
Hubei & 0.315 & 0.331 & 0.331 & 0.351 & 0.363 & 0.389 & 0.394 & 0.403 & 0.414 & 0.425 & 0.372 & Acceptable \\
Hunan & 0.325 & 0.337 & 0.333 & 0.348 & 0.331 & 0.344 & 0.372 & 0.371 & 0.391 & 0.418 & 0.357 & Acceptable \\
Jiangxi & 0.242 & 0.250 & 0.228 & 0.237 & 0.234 & 0.247 & 0.279 & 0.290 & 0.316 & 0.331 & 0.265 & Acceptable \\
Jiangsu & 0.691 & 0.736 & 0.697 & 0.855 & 0.847 & 0.576 & 0.597 & 0.589 & 0.614 & 0.635 & 0.684 & Good \\
Anhui & 0.285 & 0.307 & 0.309 & 0.361 & 0.382 & 0.397 & 0.401 & 0.410 & 0.427 & 0.457 & 0.374 & Acceptable \\
Zhejiang & 0.649 & 0.672 & 0.635 & 0.701 & 0.721 & 0.705 & 0.695 & 0.715 & 0.568 & 0.598 & 0.666 & Good \\
Yunnan & 0.377 & 0.385 & 0.359 & 0.384 & 0.391 & 0.414 & 0.409 & 0.423 & 0.481 & 0.522 & 0.415 & Acceptable \\
Sichuan & 0.286 & 0.313 & 0.298 & 0.329 & 0.342 & 0.367 & 0.374 & 0.400 & 0.426 & 0.442 & 0.358 & Acceptable \\
Guizhou & 0.080 & 0.096 & 0.115 & 0.112 & 0.121 & 0.150 & 0.164 & 0.188 & 0.245 & 0.295 & 0.156 & Bad \\
\hline
\end{tabular}

governance is somehow a monetary burden for regions, and there is hysteresis for the effects of water governance; besides, the tourism resources and foundation are more qualified, and the tourism industry is more focused in these regions as it is a useful approach to stimulate social and economic development.

The average DDs of the two subsystems are shown in Figure 3 to compare spatial distributions. The DDs of water governance and tourism subsystems were geographically similar: compared with the upstream and middle reaches (the west and the middle parts), the downstream (the east part) was relatively higher. For the downstream, Shanghai in the water governance subsystem was apparently in a better grade due to the great efforts in water governance response such as the investment of wastewater treatment and water saved per person; three regions were higher in DD in the tourism subsystem due to the rich resources, advanced infrastructure, large numbers of tourists, and so on. For the upstream reaches, Chongqing in the water governance ranked in a worse situation mainly due to the relative lack of investment in wastewater treatment and the action of saving water per capita; Guizhou in the tourism subsystem had lower grade mainly because of the fewer tourists, less tourism income, and underdeveloped infrastructure. Generally, the downstream is higher in DD mainly due to the resource endowments, financial endeavors of authorities, public participation, and so on.
5.2. Spatial-Temporal Analysis of DCC. Table 6 and Figure 4 show the evolution of DCC with time. From the temporal perspective, most regions remained stable with slight upward fluctuations. In detail, Shanghai, Zhejiang, Jiangsu, Anhui, and Hubei were mainly in the coordinated range (over 0.6), demonstrating that these places had acceptable coupling coordination status. Among them, Hubei developed from the status of reluctant coordination in 2008 (0.543) to intermediate coordination in 2017 (0.745), which was a relatively leapfrog growth. In addition, Jiangxi, Hunan, Chongqing, Sichuan, Guizhou, and Yunnan were in the range of transitional coordination (0.4-0.6) with mild fluctuation, demonstrating that the DCCs were in the transitional status with the benign development trends. It is noticeable that Guizhou developed from a slight imbalance in 2009 (0.371) to reluctant coordination in 2018 (0.507), also exhibiting a leapfrog growth. The trend of upward fluctuations is mainly because of the deeper understanding of the interaction mechanism of the two subsystems, and the efforts of the regions to smartly use these two subsystems to affect and support each other.

Figure 5 shows the spatial evolution of DCC. There are several findings. (1) The distribution of DCC's classification was unbalanced with the downstream higher and the upstream lower. The downstream was higher in DCC mainly because of the more investment in water governance, the efficiency of water saving, the advanced development of the 

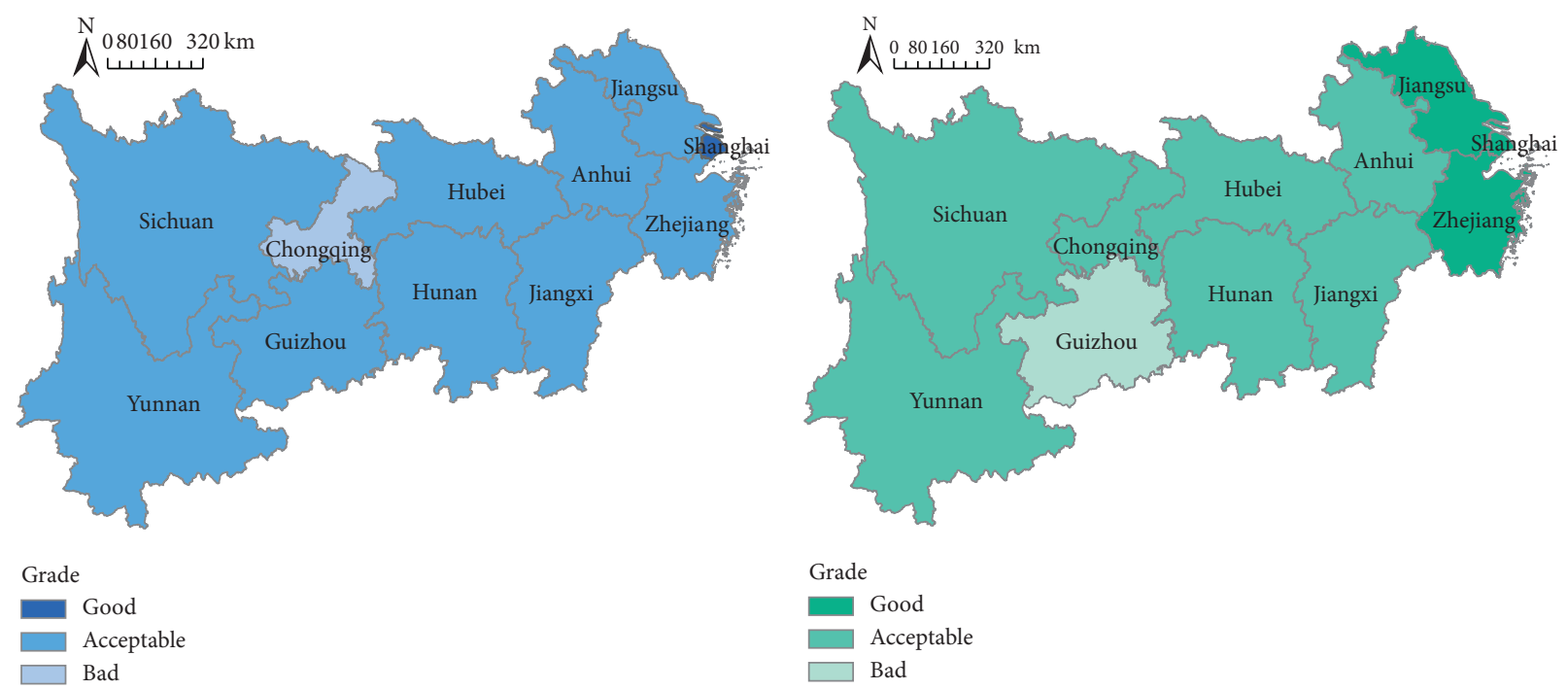

(a)

(b)

FIgURE 3: Average DD's spatial distribution. (a) Water governance subsystem and (b) tourism subsystem.

TABle 6: The DCC of the system.

\begin{tabular}{lllllllllll}
\hline & 2009 & 2010 & 2011 & 2012 & 2013 & 2014 & 2015 & 2016 & 2017 & 2018 \\
\hline Chongqing & 0.435 & 0.450 & 0.507 & 0.516 & 0.512 & 0.494 & 0.491 & 0.501 & 0.443 & 0.465 \\
Shanghai & 0.682 & 0.684 & 0.808 & 0.783 & 0.773 & 0.761 & 0.761 & 0.758 & 0.692 & 0.722 \\
Hubei & 0.543 & 0.532 & 0.609 & 0.616 & 0.609 & 0.605 & 0.609 & 0.622 & 0.745 & 0.753 \\
Hunan & 0.489 & 0.515 & 0.587 & 0.581 & 0.592 & 0.592 & 0.585 & 0.605 & 0.548 & 0.569 \\
Jiangxi & 0.446 & 0.430 & 0.506 & 0.513 & 0.519 & 0.528 & 0.532 & 0.562 & 0.506 & 0.519 \\
Jiangsu & 0.691 & 0.694 & 0.798 & 0.831 & 0.798 & 0.775 & 0.777 & 0.775 & 0.702 & 0.740 \\
Anhui & 0.677 & 0.697 & 0.552 & 0.625 & 0.637 & 0.651 & 0.648 & 0.650 & 0.606 & 0.615 \\
Zhejiang & 0.741 & 0.635 & 0.729 & 0.745 & 0.760 & 0.777 & 0.775 & 0.788 & 0.678 & 0.699 \\
Yunnan & 0.514 & 0.498 & 0.575 & 0.610 & 0.631 & 0.605 & 0.603 & 0.626 & 0.569 & 0.577 \\
Sichuan & 0.500 & 0.547 & 0.566 & 0.597 & 0.602 & 0.600 & 0.608 & 0.628 & 0.563 & 0.642 \\
Guizhou & 0.371 & 0.384 & 0.468 & 0.406 & 0.453 & 0.458 & 0.468 & 0.485 & 0.463 & 0.507 \\
\hline
\end{tabular}

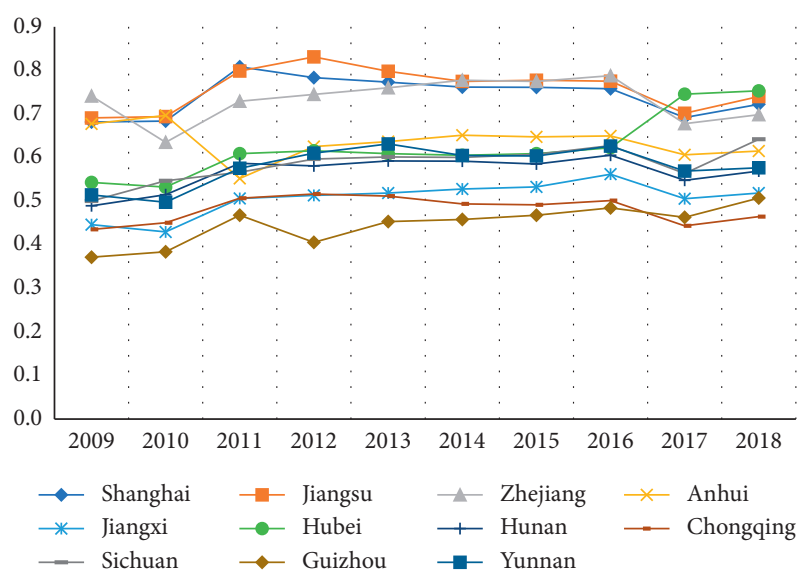

Figure 4: Evolution of the system's DCC.

tourism industry, and so on. This also exhibited the high effectiveness and efficiency of the local administrative management in the downstream regions. (2) Hubei was leading the coupling coordination development in the middle reaches (Hubei, Hunan, and Jiangxi), which was mainly because of the efforts in water governance response and tourism performance. Due to the geographical advantages in China, Hubei was easier to act as the model in coordination development between the two subsystems within the middle reaches. (3) In the upstream, though the overall trend of the DCC was upward, the gap of the DCC within this area was obvious: Chongqing and Guizhou were much lower in DCC than Sichuan and Yunnan. Specifically, Guizhou and Chongqing were lower mainly because of the limit of water governance status, tourism scale and performance, and so on. It is also noticeable that the gap of DCC between the upstream and the downstream was decreasing gradually in this decade mainly because of the emphasis of water governance and tourism industry for the upstream regions; besides, with the strategy of Poverty Alleviation through Tourism and the policy of Environmental Supervision, the upstream regions increased the DCC and diminished the differences with the downstream regions.

5.3. DCC Prediction. Table 7 shows the prediction of the water governance-tourism system's DCC in the 11 regions of the Zone. The data passed the accuracy testing, proving that the model can be utilized for further predictions [46]. 

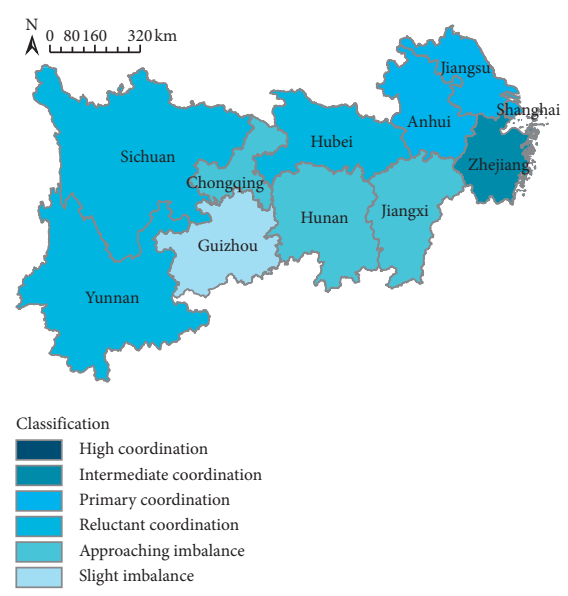

(a)
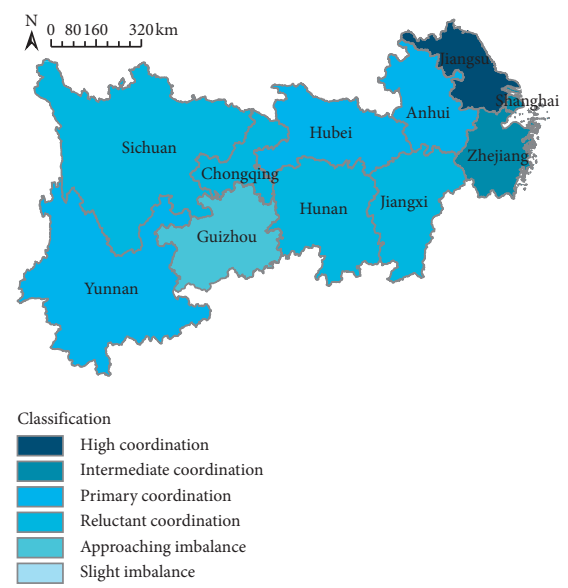

(d)
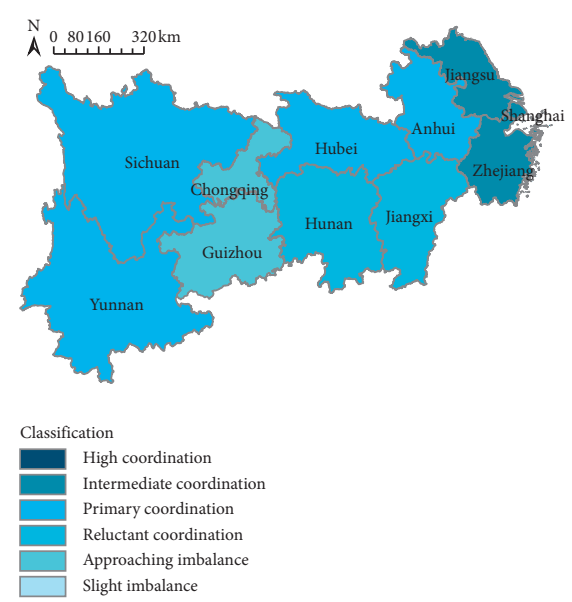

(g)
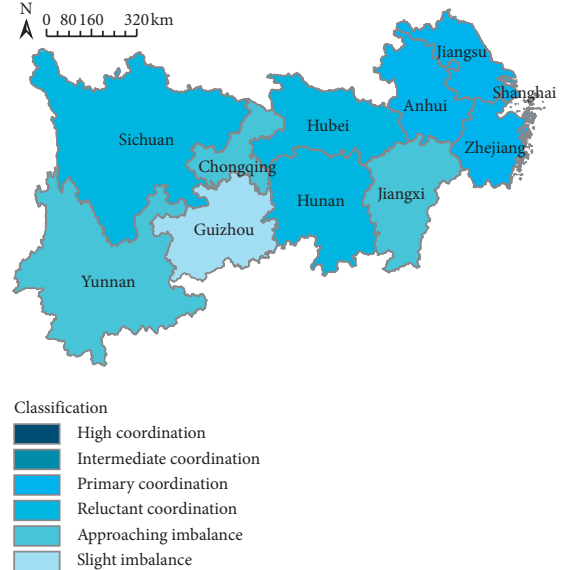

(b)
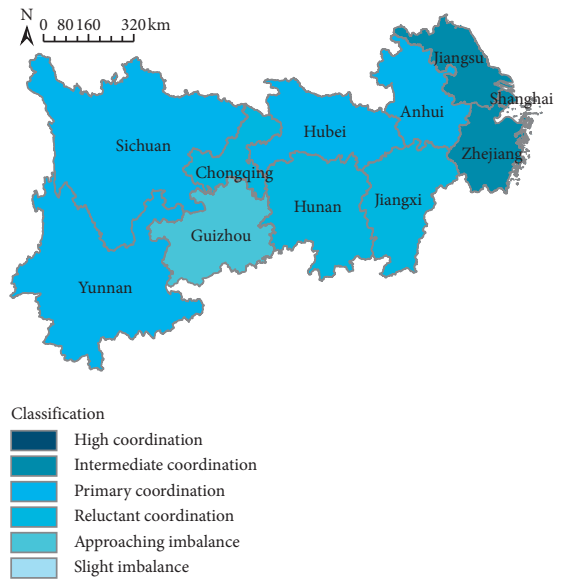

(e)
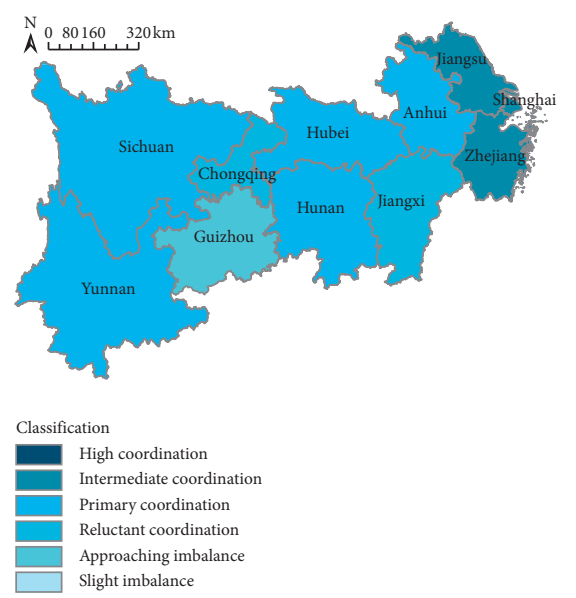

(h)
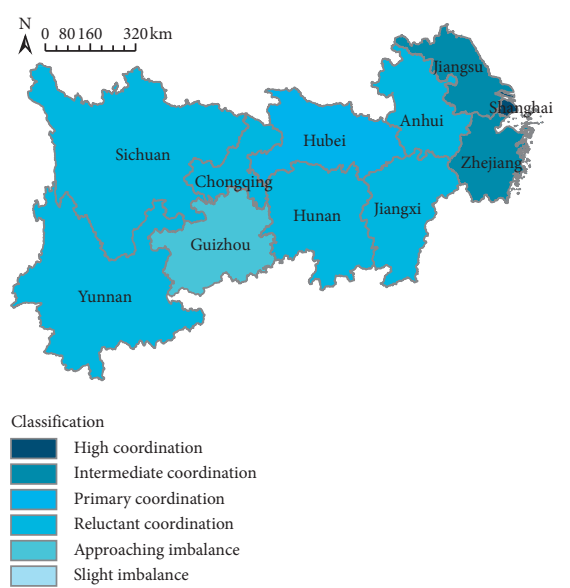

(c)

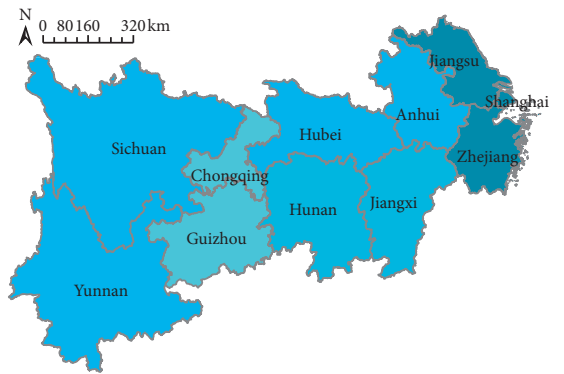

Classification

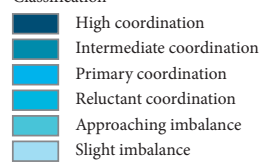

(f)
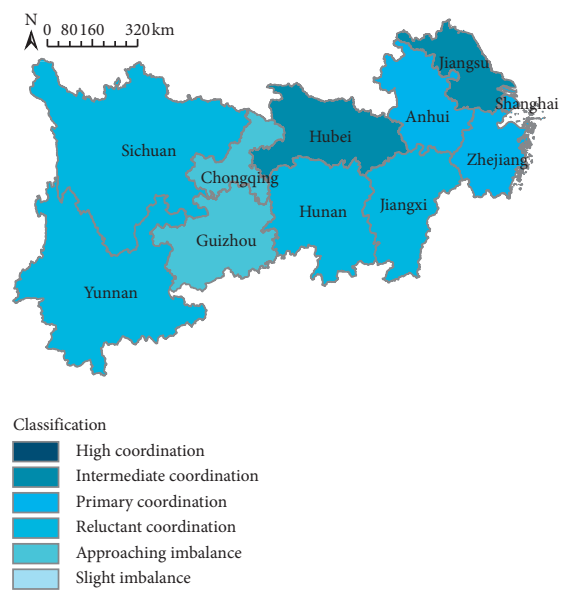

(i)

Figure 5: Continued. 


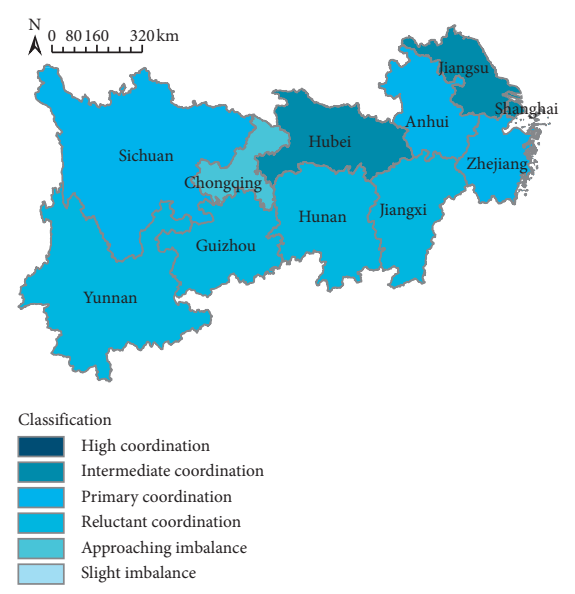

(j)

FIGURE 5: Spatial evolution of DCC. (a) 2009; (b) 2010; (c) 2011; (d) 2012; (e) 2013; (f) 2014; (g) 2015; (h) 2016; (i) 2017; (j) 2018.

The DCCs of the system in the next 4 years (2019-2022) show almost the same trends as in the last decade for most regions, and the gaps among regions will further reduce. Particularly, for the regions in the coordinated range ( 0.6 or higher), Hubei will be the leading region with the best performance from the intermediate coordination classification (0.7-0.8) to the high coordination classification (above 0.8); Shanghai and Jiangsu will face a slight decline within the classification of intermediate coordination (0.70.8 . Besides, for the regions in the transitional range (0.4-0.6), most regions will gradually develop and narrow the gaps with the highly coordinated regions; The exception is Chongqing whose DCC will decline slightly within the approaching imbalance classification (0.4-0.5). It is also noticeable that the DCC in certain upstream regions will be higher than certain regions in the downstream: Sichuan (the upstream region) has surpassed Anhui (the downstream region) since 2018 and will continue this status for the next 4 years, and also Yunnan (in the upstream) will surpass Anhui in the year 2021. This proves that the endeavors of the upstream in water governance and tourism growth gradually have positive effects.

In general, the overall tendency of DCC of the Zone for the next 4 years is upward and the gaps among regions will narrow, while the growth rates vary and certain regions will witness a decline. The coupling coordination development of the Zone requires regions to discover suitable, specific, and generalizable solutions and strategies so that the harmonious coordination of water governance and tourism industry can be enhanced.

\section{Countermeasures}

The coupling coordination of water governance and tourism of the Zone shows differences temporally and spatially, so it is important for the regions to take corresponding measures to enhance the DCC. This study proposes certain countermeasures based on the example of the Zone, which are specific while generalizable to other places.
In the downstream where the water governance and tourism are relatively highly coordinated, regions need to find cooperative and creative ways to further increase the DCC and prevent future potential decline. There are two countermeasures particularly. (1) The first is to enhance cross-regional interaction and cooperation in order to generate spillover effects of water governance and tourism on the rest regions. Further cooperation systems among regions should be explored by establishing consultation mechanism, initiating academic forums or exchange programs, and so on. (2) The second is to explore the new approaches of water governance and tourism development with the up-to-date technology. For instance, big data and blockchains can be applied as new approaches to scientifically enhance coordination growth.

In the middle reaches where a certain place (such as Hubei) is playing the leading role meanwhile the others (Hunan and Jiangxi) are performing at the average status, the regions need to look for the specific weaknesses and take integrated measures to enhance the coupling coordination development. There are several countermeasures. (1) First is to construct city clusters and achieve integrative development within the reaches. Destination integrated management should be considered as a whole and develop the facilities, transportation, and infrastructures synchronously within the city cluster. (2) Second is to accelerate public administration reform and institutional innovation and make use of social capital to further enhance the effectiveness of destination integrated management. Authorities should research the action mechanism between public administration reform and social participation and encourage society to join in the coupling coordination development of the system.

In the upstream where the water governance and tourism are relatively restricted (such as Guizhou and Chongqing), the regions are required to make comprehensive destination management strategies and pay more efforts in increasing the DCC. The following countermeasures are applicable for such regions. (1) First is to 
TABle 7: Prediction of DCC.

\begin{tabular}{lccccccr}
\hline & $a$ & & & & \multicolumn{3}{c}{ Prediction year } \\
& & $r$ & $C$ & $P$ & 2019 & 2020 & 2021 \\
\hline Chongqing & 0.006 & -0.286 & 0.803 & 0.500 & 0.472 & 0.469 & 0.466 \\
Shanghai & 0.006 & 1.392 & 0.844 & 0.700 & 0.729 & 0.725 & 0.721 \\
Hubei & -0.035 & 1.248 & 0.481 & 0.900 & 0.752 & 0.779 & 0.807 \\
Hunan & -0.004 & -0.406 & 0.676 & 0.700 & 0.586 & 0.589 & 0.591 \\
Jiangxi & -0.015 & -9.188 & 0.686 & 0.700 & 0.551 & 0.559 & 0.567 \\
Jiangsu & 0.005 & 0.486 & 0.852 & 0.700 & 0.747 & 0.743 & 0.739 \\
Anhui & 0.003 & -3.357 & 0.924 & 0.800 & 0.623 & 0.621 & 0.619 \\
Zhejiang & -0.004 & -3.802 & 0.983 & 0.400 & 0.748 & 0.751 & 0.753 \\
Yunnan & -0.008 & 1.789 & 0.805 & 0.500 & 0.613 & 0.618 & 0.736 \\
Sichuan & -0.012 & -1.357 & 0.533 & 0.900 & 0.632 & 0.640 & 0.618 \\
Guizhou & -0.024 & 1.319 & 0.503 & 0.900 & 0.511 & 0.523 & 0.647 \\
\hline
\end{tabular}

increase social awareness of the importance of water governance and tourism growth by providing necessary education and training, so that the service quality of tourism events, hotels, transportations, and so on can be enhanced, and the pressure of water governance can be reduced. How and what to teach citizens should be further discussed for the authorities. (2) Second is to take advantage of interregional cooperation and national strategies and accelerate the coupling coordination with such external impetus so that a new growth model of coupling coordination with sustainability would be achieved. How to transform national strategies to specific schedules which can be applied to destination management is the further direction of research.

\section{Conclusions and Future Prospects}

This study empirically examines and predicts the development of coupling coordination of water governance and tourism with the example of the Zone between 2009 and 2018 and gets the following conclusions:

(1) In general, the DDs of the water governance subsystem are averagely lower and more fluctuant. Spatially, the DDs of the two subsystems have a geographical similarity: the downstream is higher than the other reaches.

(2) For DCC, temporally, most regions have mild upward fluctuations except certain downstream regions. Spatially, the distribution of DCC is unbalanced with the downstream higher than other regions, Hubei higher within the middle reaches, and Chongqing and Guizhou lower within the upstream.

(3) The DCC in the next 4 years shows almost the same trend, and the gaps among regions will narrow with varied growth rates. Such differences require regions to discover suitable, specific, and generalizable solutions for better coordination development.

There are several contributions to this study.

(1) The study analyzes the correlation mechanism between water governance and tourism from the perspective of academic rationality, which answers the question that whether and how the water governance and tourism interact with each other theoretically.

(2) Based on the correlation mechanism, this study establishes the water governance-tourism evaluation system, which is composite and aggregate, for objective analysis and effective reference of the coupling coordination relationship between the two subsystems.

(3) The cross-regional temporal and spatial comparisons break former research's limitations on a single region without mutual comparisons, and the predictions of DCC contribute to better understanding the coupling coordination relationship, exploring regional differences, and providing corresponding countermeasures in water governance and tourism development.

This study has certain limitations. Due to the limited accessibility of statistical data, this study mainly considers measurable indicators only; obviously, the evaluation system should be multidimensional and comprehensive in indicators. Therefore, this issue needs to be further analyzed and discussed in the future.

\section{Data Availability}

The data used to support the findings of this study are available from the corresponding author upon request.

\section{Conflicts of Interest}

The authors declare no conflicts of interest.

\section{Authors' Contributions}

Conceptualization, methodology, validation, formal analysis, investigation, resources, data curation, writing the original draft preparation, supervision, project administration, and funding acquisition were contributed by Y. G; software, Y. G. and H. Z.; reviewing and editing the manuscript, M. M. and H. Z.; visualization, M. M. 


\section{Acknowledgments}

This research was funded by Shanghai Municipal Education Commission (Grant no. ZZSDJU19012), Shanghai CCP Committee of Education and Health Work (Grant no. TZYJ2019-B37), and Shanghai Dianji University (Grant no. 19AR20).

\section{References}

[1] J. Dawson and K. Lupton, "Book review," Annals of Tourism Research, vol. 60, pp. 185-187, 2016.

[2] Z. Zhuang, S. Yan, W. Wen, and Y. Yilin, "Study on the utilization and protection of water resources in the ecotourism development of the Boluo lake wetland nature reserve in Jilin Province," Desalination and Water Treatment, vol. 169, pp. 114-119, 2019.

[3] L. L. Wang and H. Q. Zhang, "The impact of marine tourism resources development on sustainable development of marine economy," Journal of Coastal Research, vol. 94, no. 1, pp. 589-592, 2019.

[4] X. Luo and W. Zhong, "Wetland tourism park ecology and its application in water pollution control," Desalination and Water Treatment, vol. 125, pp. 211-216, 2018.

[5] S. Gedik and S. Mugan-Ertugral, "The effects of marine tourism on water pollution," Fresenius Environmental Bulletin, vol. 28, pp. 863-866, 2019.

[6] M. A. Lizardi-Jiménez, R. M. Leal-Bautista, A. Ordaz, and R. Reyna-Velarde, "Airlift bioreactors for hydrocarbon water pollution remediation in a tourism development pole," Desalination and Water Treatment, vol. 54, no. 1, pp. 44-49, 2015.

[7] A. K. Biswas, "Interactive approaches to water governance in Asia edited by Kenji Otsuka, Singapore, Springer, 2019, viii +225 pp," The Developing Economies, vol. 58, no. 1, pp. 82-85, 2019.

[8] D. Whittington and W. Xun, "Editorial Improving water governance in Kathmandu: insights from systems thinking and behavioral science," Water Policy, vol. 21, no. 1, pp. 1-8, 2019.

[9] D. Kutzner, "Environmental change, resilience, and adaptation in nature-based tourism: conceptualizing the socialecological resilience of birdwatching tour operations," Journal of Sustainable Tourism, vol. 27, no. 8, pp. 1142-1166, 2019.

[10] A. Lapko, R. Strulak-Wojcikiewicz, M. Landowski, and R. Wieczorek, "Management of waste collection from yachts and tall Ships from the perspective of sustainable water tourism," Sustainability, vol. 11, no. 1, p. 121, 2019.

[11] M. Kaaristo and S. Rhoden, "Everyday life and water tourism mobilities: mundane aspects of canal travel," Tourism Geographies, vol. 19, no. 1, pp. 78-95, 2017.

[12] A. E. Scheepens, J. G. Vogtländer, and J. C. Brezet, “Two life cycle assessment (LCA) based methods to analyse and design complex (regional) circular economy systems. Case: making water tourism more sustainable," Journal of Cleaner Production, vol. 114, pp. 257-268, 2016.

[13] X. Guo, M. S. Ho, L. You et al., "Industrial water pollution discharge taxes in China: a multi-Sector dynamic analysis," Water, vol. 10, no. 12, p. 1742, 2018.

[14] J. Rosselló, M. Santana-Gallego, and W. Awan, "Infectious disease risk and international tourism demand," Health Policy and Planning, vol. 32, pp. 177-548, 2017.

[15] D. Badau and A. Badau, "The motric, educational, recreational and satisfaction impact of adventure education activities in the urban tourism environment," Sustainability, vol. 10, no. 6, p. 2106, 2018.

[16] J. Han, "Carrying capacity of low carbon tourism environment in coastal areas from the perspective of ecological efficiency," Journal of Coastal Research, vol. 83, no. 1, pp. 199-203, 2018.

[17] C. Liu, R. Zhang, M. Wang, and J. Xu, "Measurement and prediction of regional tourism sustainability: an analysis of the Yangtze river economic zone, China," Sustainability, vol. 10, no. 5, p. 1321, 2018.

[18] J. J. Schmidt and C. Z. Peppard, "Water ethics on a humandominated planet: rationality, context and values in global governance," Wiley Interdisciplinary Reviews: Water, vol. 1, no. 6, pp. 533-547, 2014.

[19] A. Gabarda-Mallorquí, X. Garcia, and A. Ribas, "Mass tourism and water efficiency in the hotel industry: a case study," International Journal of Hospitality Management, vol. 61, pp. 82-93, 2017.

[20] S. Cole and M. Browne, "Tourism and water inequity in bali: a social-ecological systems analysis," Human Ecology, vol. 43, no. 3, pp. 439-450, 2015.

[21] J.-H. Zhang, Y. Zhang, J. Zhou, Z.-H. Liu, H.-L. Zhang, and Q. Tian, "Tourism water footprint: an empirical analysis of Mount Huangshan," Asia Pacific Journal of Tourism Research, vol. 22, no. 10, pp. 1083-1098, 2017.

[22] Á.-F. Morote, D. Saurí, and M. Hernández, "Residential tourism, swimming pools, and water demand in the western mediterranean," The Professional Geographer, vol. 69, no. 1, pp. 1-11, 2017

[23] A. Hof and M. Blázquez-Salom, "Changing tourism patterns, capital accumulation, and urban water consumption in Mallorca, Spain: a sustainability fix?" Journal of Sustainable Tourism, vol. 23, no. 5, pp. 770-796, 2015.

[24] G. T. LaVanchy and M. J. Taylor, "Tourism as tragedy? Common problems with water in post-revolutionary Nicaragua," International Journal of Water Resources Development, vol. 31, no. 4, pp. 765-779, 2015.

[25] J. P. Siwek and W. Biernacki, "Effect of tourism-generated wastewater on biogenic ions concentrations in stream water in Tatra national park (Poland)," Eco. Mont (Journal on Protected Mountain Areas Research), vol. 8, no. 2, pp. 43-52, 2016.

[26] E. Toth, C. Bragalli, and M. Neri, “Assessing the significance of tourism and climate on residential water demand: panel-data analysis and non-linear modelling of monthly water consumptions," Environmental Modelling \& Software, vol. 103, pp. 52-61, 2018.

[27] Y. Zhu, Q. Zhu, and Z. Zhu, "Modeling, evaluation and analysis of tourism destination competitiveness: a case study of the Yangtze river Delta of China," Asia Pacific Journal of Tourism Research, vol. 19, no. 8, pp. 932-949, 2014.

[28] Z. Tang, "An integrated approach to evaluating the coupling coordination between tourism and the environment," Tourism Management, vol. 46, pp. 11-19, 2015.

[29] E. Kushi, "Sustainable tourism and environment protection in Albania," Journal of Environmental Protection and Ecology, vol. 12, pp. 251-257, 2011.

[30] L. Li and G. Weng, "An integrated approach for spatial analysis of the coupling relationship between tourism footprint and environment in the Beijing-Tianjin-Hebei region of China," Asia Pacific Journal of Tourism Research, vol. 21, no. 11, pp. 1198-1213, 2016.

[31] Y. Geng, Z. Wei, H. Zhang, and M. Maimaituerxun, “Analysis and prediction of the coupling coordination relationship between tourism and Air environment: Yangtze river 
economic zone in China as example," Discrete Dynamics in Nature and Society, vol. 2020, Article ID 1406978, 15 pages, 2020.

[32] D. Cui, X. Chen, Y. Xue, R. Li, and W. Zeng, “An integrated approach to investigate the relationship of coupling coordination between social economy and water environment on urban scale-a case study of Kunming," Journal of Environmental Management, vol. 234, pp. 189-199, 2019.

[33] J. Liu, C. Li, J. Tao, Y. Ma, and X. Wen, "Spatiotemporal coupling factors and mode of tourism industry, urbanization and ecological environment: a case study of Shaanxi, China," Sustainability, vol. 11, no. 18, p. 4923, 2019.

[34] M. Xu, C. Chen, and X. Deng, "Systematic analysis of the coordination degree of China's economy-ecological environment system and its influencing factor," Environmental Science and Pollution Research, vol. 26, no. 29, pp. 2972229735, 2019.

[35] Y. Li, Y. Li, Y. Zhou, Y. Shi, and X. Zhu, "Investigation of a coupling model of coordination between urbanization and the environment," Journal of Environmental Management, vol. 98, pp. 127-133, 2012.

[36] L. Ding, W. Zhao, Y. Huang, S. Cheng, and C. Liu, "Research on the coupling coordination relationship between urbanization and the air environment: a case study of the area of Wuhan," Atmosphere, vol. 6, no. 10, pp. 1539-1558, 2015.

[37] J.-H. Huang and K.-H. Peng, "Fuzzy rasch model in TOPSIS: a new approach for generating fuzzy numbers to assess the competitiveness of the tourism industries in Asian countries," Tourism Management, vol. 33, no. 2, pp. 456-465, 2012.

[38] Q. Wang, Z. Mao, L. Xian, and Z. Liang, "A study on the coupling coordination between tourism and the low-carbon city," Asia Pacific Journal of Tourism Research, vol. 24, no. 6, pp. 550-562, 2019.

[39] K.-C. Liao, M.-Y. Yue, S.-W. Sun et al., "An evaluation of coupling coordination between tourism and finance," Sustainability, vol. 10, no. 7, p. 2320, 2018.

[40] A. G. Asmelash and S. Kumar, "Assessing progress of tourism sustainability: developing and validating sustainability indicators," Tourism Management, vol. 71, pp. 67-83, 2019.

[41] G. Goffi and M. Cucculelli, "Explaining tourism competitiveness in small and medium destinations: the Italian case," Current Issues in Tourism, vol. 22, no. 17, pp. 2109-2139, 2019.

[42] H. J. Xue, "Research on synchronous coordination development of tourism-economy-environment system in Qinghai section of silk road," IOP Conference Series: Earth and Environmental Science, vol. 108, 2018.

[43] Q. Zheng, Y. Kuang, and N. Huang, "Coordinated development between urban tourism economy and transport in the pearl river delta, China," Sustainability, vol. 8, no. 12, p. 1338, 2016.

[44] Z. Du, Y. Hu, and N. A. Buttar, "Analysis of mechanical properties for tea stem using grey relational analysis coupled with multiple linear regression," Scientia Horticulturae, vol. 260, Article ID 108886, 2020.

[45] M. Cheng and G. Shi, "Improved methods for parameter estimation of gray model GM $(1,1)$ based on new background value optimization and model application," Communications in Statistics-Simulation and Computation, vol. 49, pp. 1-23, 2019.

[46] L. Gong and C. Wang, "Model of automobile parts sale prediction based on nonlinear periodic gray GM $(1,1)$ and empirical research," Mathematical Problems in Engineering, vol. 2019, Article ID 3620120, 8 pages, 2019. 